\title{
A mixed-methods evaluation of a group based trail walking program to reduce anxiety in cancer survivors
}

\author{
I. A. Lesser ${ }^{1 *}$ D, J. Prystupa', L. Belanger ${ }^{2}$, C. Thomson ${ }^{3}$ and C. P. Nienhuis ${ }^{1}$
}

\begin{abstract}
Background: Cancer survivorship results in an increased number of physical and psychosocial health issues. Engaging in physical activity in natural environments is often thought of as restorative. Despite the potential benefits of engaging in physical activity in natural environments there are no sustainable community-based programs for cancer survivors that employ this form of physical activity. This study aims to evaluate the impact of an 8-week trail-walking (TW) program on anxiety in a population of adult cancer survivors.

Methods: The TW program consisted of two trail walks per week for 8 weeks led by a hiking guide. Individuals were eligible to participate if they were 19 years or older, were a cancer survivor, were not on active immunotherapy, and had medical clearance from their physician for physical activity. While 12 participants signed up for the program, 9 participants ( $N=9,8 \mathrm{~F}, 1 \mathrm{M}$ ) completed the program. A mixed methodology included preand-post quantitative program surveys and post-program interviews. Questionnaires measured generalized anxiety, sleep disturbances, self-efficacy, self-esteem, psychological well-being and depression as well as pre-and-post hike state anxiety. Data was analysed using paired t-tests. Interviews were transcribed verbatim and an inductive thematic analysis was conducted to consolidate meaning and identify themes using NVivo 11 software.
\end{abstract}

Results: Average attendance was $74 \%$ of the 16 hikes. There was no significant reduction in the primary outcome of generalized anxiety $(p=.38)$. There was a significant reduction in perceived stress after 8 -weeks $(p=.03)$ and a significant reduction in state anxiety after TW $(p<.001)$. None of the other secondary outcomes were statistically significant $(p>$.05). Four overarching themes, or benefits, emerged from qualitative data analysis: (a) benefits of program design (b) physical benefits, (c) psychological benefits, and (d) social benefits.

Conclusions: These findings demonstrate the utility of a TW program for cancer survivors in order to promote physical, psychological and social health. Feasibility of a TW program would be contingent on access to natural areas for TW and an instructor-led program with other cancer survivors.

Keywords: Cancer survivors, Nature, Physical activity, Social support, Trail walking, Self-efficacy

\section{Background}

In Canada, cancer is the number one cause of death with one in four Canadians dying of cancer and a five-year survival rate of $63 \%$ [10]. A cancer survivor is defined as a person who has been diagnosed with cancer, starting

\footnotetext{
* Correspondence: iris.lesser@ufv.ca

${ }^{1}$ School of Kinesiology, University of the Fraser Valley, Chilliwack, BC, Canada Full list of author information is available at the end of the article
}

the day of diagnosis until the end of life [3]. Advances in medical research, early detection, and increasing numbers of treatment options have improved cancer survival rates and estimates show there are approximately one million cancer survivors currently in Canada [9]. Cancer survivors tend to have poorer health outcomes and decreased health-related quality of life compared to similar individuals without a history of cancer [18, 33]. The poorer health outcomes of cancer survivors are found to

(c) The Author(s). 2020 Open Access This article is licensed under a Creative Commons Attribution 4.0 International License, which permits use, sharing, adaptation, distribution and reproduction in any medium or format, as long as you give appropriate credit to the original author(s) and the source, provide a link to the Creative Commons licence, and indicate if changes were made. The images or other third party material in this article are included in the article's Creative Commons licence, unless indicated otherwise in a credit line to the material. If material is not included in the article's Creative Commons licence and your intended use is not permitted by statutory regulation or exceeds the permitted use, you will need to obtain permission directly from the copyright holder. To view a copy of this licence, visit http://creativecommons.org/licenses/by/4.0/. 
be independent of the time since diagnosis [33]. For cancer survivors who develop chronic conditions, they display higher symptom prevalence, especially in sensation abnormality, pain, and fatigue, when compared to individuals without cancer [18]. They are also at increased risk of functional loss, secondary cancers, and chronic diseases, making them a high-risk group often targeted for behavioral interventions [14].

Physical activity has been shown to increase quality of life in cancer survivors, specifically improving aerobic fitness, muscular strength, body composition, and reducing prevalence of depression and anxiety [16]. The American College of Sports Medicine (ACSM) supports physical activity as exercise prescription to help address the unique health challenges of cancer survivors [11] and recommends 150 min of moderate-vigorous physical activity per week as suggested for the general population. American cancer survivors were recorded taking anxiety and depression medications at twice the rate of the general population [12]. Distress, anxiety, and depression have been shown to linger for up to 10 years after cancer treatment [35]. When a person is diagnosed with cancer, major life adjustments need to be made due to the many physical, emotional, social, and financial demands involved [21]. These demands can feel overwhelming even when the individual has access to the best coping techniques. Cancer survivors often report feelings of loneliness and fear and admit to becoming hypervigilant to physical sensations as lingering memories spur on feeling of anxieties of cancer recurrence [35].

Natural environments are often thought of as restorative, offering a setting for physical and psycho-emotional renewal and recovery [22]. Research has indicated that exposure to nature increases positive psychological health outcomes such as happiness, mood and selfesteem, enhances vitality, and reduces stress [26]. A reduction in both state and trait anxiety has been seen in individuals who feel a stronger connection to nature through physical exposure and familiarity with nature [23]. Recent evidence suggests that spending at least 120 min per week in nature results in consistently higher levels of health and well-being compared to those who experience less nature exposure [34].

The majority of the literature on the relationship between nature and mental health is in healthy populations and individuals who are already physically active. Little literature exists to help understand the human-nature interaction with those who have lived through experiences of ill-health and disease [8]. Preliminary investigations of nature-based interventions, such as hospital rehabilitation gardens, retreats in natural settings, and views of natural landscapes have shown potential to ease the strain and impact of diseases within a healthcare context [8]. Understanding cancer survivor's perspective of how nature contributes to their recovery will better help identify intervention to address the unique challenges that cancer survivors encounter [8]. Doing activities in the natural environment, as opposed to in a hospital or gym setting, may help cancer survivors strengthen ties to activities they consider normal, as opposed to cancer related [8].

The effectiveness of green exercise (exercising in a natural environment) to reduce anxiety levels in cancer survivors is an understudied area of research. This study aims to evaluate the impact of an 8-week trail-walking (TW) program on anxiety in a population of adult cancer survivors. It is hypothesized that cancer survivors who participate in the eight-week TW program will see a reduction in generalized anxiety as well as improvements in other psychosocial and physical activity outcomes: state anxiety, perceived stress, sleep, exercise self-efficacy, self-esteem, psychological well-being, and depression. To further support quantitative data, interviews were conducted with participants to better understand the program impact on their physical and psychosocial health.

\section{Methods \\ Program design}

The TW program consisted of two trail walks per week for 8 weeks led by a qualified hiking guide. The hiking guide was certified with an outdoor leadership degree and worked as a physiotherapy assistant, and a certified exercise physiologist supervised the program. To maximize physical and psychological benefits, weekly trail walking times totaled $\geq 150$ minutes per week in accordance with recommended physical activity guidelines ( $150 \mathrm{~min} /$ week $)$ (reference) as well as recommend nature exposure guidelines of (120 min/week) [34]. One trail had $70 \mathrm{~m}$ of elevation gain over $3 \mathrm{kms}$ and the other had $175 \mathrm{~m}$ of elevation gain over $4 \mathrm{kms}$. Both trails passed through lush green old growth forest. Fitness and comfort of participants on trails were used to inform pace setting and breaks. As the participants became more comfortable with the trails, the group increased moving time and distance travelled. The leader also carried a backpack with a basic first aid kit, bear spray, a whistle, water, headlamps, and extra layers. Trekking poles and basic hiking gear (rain jacket, water bottle, warm layers, backpack) were also made available.

\section{Participants}

Participants were recruited from the Fraser Valley, British Columbia, Canada, a community with a population of approximately 300,000. Participants were recruited through social media, local newspapers, poster advertisements, and with the help of local medical offices and the $\mathrm{BC}$ Cancer Center. Individuals were eligible to participate if they were 19 years or older, were a cancer survivor, were not on active immunotherapy, and had 
medical clearance from their physician for physical activity.

\section{Study measures}

Participants completed questionnaires using an online survey software (SurveyMonkey). Pre-study questionnaires consisted of personal demographics (age, sex, marital status, education), cancer related history and other medical variables. Pre-post surveys were used to assess general anxiety, quality of life, stress, sleep, exercise self-efficacy, self-esteem, psychological well-being, depression, and current levels of physical activity. Other variables measured were used to assess the acute effects of the TW program and consisted of state anxiety and self-reported exercise intensity and were recorded by pen and paper at the location of the TW.

\section{Primary outcome}

Anxiety The generalized anxiety disorder (GAD-7) scale was used to assess changes in anxiety. The GAD-7 is considered an excellent screening tool for identifying people with generalized anxiety disorders [27]. The validity of GAD-7 was substantiated in a primary care sample with a sensitivity value of .89 and a specificity value of .82 [27] and has been shown to be valid and reliable [5]. In the current study, the scale demonstrated high internal consistency (alpha $=0.89$ ) and intercorrelations with the PHQ-2 and the Rosenberg Self-Esteem Scale were $\mathrm{r}=.64(P<.001)$ and $\mathrm{r}=-.43(P<.001)$.

\section{Secondary outcomes}

State anxiety The Visual Analog Scale (VAS) was used to assess changes in state anxiety level. The VAS consists of a $100 \mathrm{~mm}$ straight line with "calm" on the left side, "anxious" on the right side, and a marker in the middle. The participant assessed his/her anxiety pre- and postTW by making a mark on the anxiety line. The VAS for the State-Trait Anxiety Inventory- State subscale (STAIState) has been reported to have a moderate test-retest reliability, $r(172)=.56, p<.001$ [2]; a highly correlated convergent validity of $r(172)=.62, p<.00$; and VAS sensitivity to changes in state anxiety was also seen to be significant with $(F(1,48)=25.13, p<.001)$ [2]. A multiitem inventories should be used as primary measures when possible [2], however the VAS has presented as a rapid, reliable and valid measurement of state anxiety and was chosen for its ease of use in the field.

Perceived stress The perceived stress scale (PSS) is a 10 -item questionnaire that is widely used as an instrument to measure the perception of stress [20]. The scale has shown adequate internal reliability (Cronbach's alpha $>.70)$, strong test-retest reliability $(>.70)$ and moderate criterion validity $(r>.70)[20]$.

Sleep The PROMIS Sleep Disturbance Scale (SD-8) was used to evaluate changes in the severity of sleep disturbances. Each item is rated on a 5-point Likert scale and rates the severity of sleep disturbance in the past 7 days. When compared to the Pittsburgh Sleep Quality Index (PSQI) and Epworth Sleepiness Scale (ESS), the SD-8 was found to both be valid and reliable [36].

Exercise self efficacy The modified Bandura's exercise self-efficacy scale was used to assess changes in exercise self-efficacy. Modified Bandura's Exercise Self-Efficacy Scale measures confidence and individual experiences in exercising regularly. This is a 9-item scale that asks participants "how sure are you that you will do each of the following..." with the response scale: very sure, pretty sure, a little sure and not at all sure with a higher score equating to greater exercise self-efficacy. The internal reliability in the current study was .88 [25].

Self esteem The Rosenberg Self Esteem Scale was used to assess changes in self-esteem. This 10-item scale measures both positive and negative feelings about oneself [31] has demonstrated high internal reliability and test-retest (.88) and moderate construct validity (46 to .71) [29].

Psychological well-being The psychological well-being 18 Item Scale (PWB-18) was used to assess changes in psychological well-being. The PWB-18 is scored on a 6point Likert scale that ranges from strongly disagree to strongly agree. The scale aims to assess how individuals perceive dimensions of well-being: autonomy, environmental mastery, personal growth, positive relations with others, purpose in life and self-acceptance [1].

Depression The Center for Epidemiologic Studies Depression Scale (CES-D 10) was used to assess changes in depression. The CES-D 10 had a Cronbach's alpha of .89 and a test-retest score of .57 when used evaluating a cancer population. The correlations between the CES-D and other depressive assessments were between .65 and .77 [17].

\section{Qualitative interviews}

Participants were purposively recruited via e-mail invitation after completing the TW program. A semistructured interview guide was developed to gain rich understanding of participant experiences within the program, as well as to permit flexibility within the interviews. Interview questions explored overall experience ("Can you describe your experience with the Take-aHike program?"), participant motivation for joining the program ("Why did you participate in the program?"), 
program impact on anxiety ("How has the program impacted your overall well-being? How has the program impacted your anxiety?"), the role of nature ("How would you describe the impact that nature had on you?") and the perceived impact of social support and preference for exercising with other cancer survivors ("What significance did the other participants have on your experience in the program?"). The interviewer was a male doctoral candidate who was trained in both qualitative research methodology and general counselling skills. This researcher was independent of the TW program, only having met participants for the purpose of the interviews. Audio-recorded interviews, which took place within a university office $(n=8)$ or via telephone $(n=1)$, ranged from 20 to $45 \mathrm{~min}$.

\section{Statistical and data analysis}

A paired t-test was used to compare the primary outcome of generalized anxiety before and after the 8-week TW program. All other variables were similarly assessed for changes before and after the program as a secondary analysis. In addition, a paired $\mathrm{t}$-test was used to compare the group mean pre and post state anxiety scores assessed with the visual analog scale of all 16 trail walks throughout the 8-week program. Statistical significance was set at $p<.05$.

Interviews were transcribed verbatim and an inductive thematic analysis was conducted to consolidate meaning and identify themes using NVivo 11 software [28]. Two researchers independently analyzed and coded the data into meaningful groups. Once complete, themes were merged and regrouped and reviewed for coherence between data and within themes, ensuring identifiable distinction between themes. Through the presentation of results, quotations are described based on age, sex, and cancer type in order to consider participant differences while preserving anonymity.

\section{Results}

While 12 participants signed up for the program, 9 participants $(N=9,8 \mathrm{~F}, 1 \mathrm{M})$ completed the TW program and agreed to participate in interviews at program completion. Three participants did not complete the program either due to limited time availability or one withdrew due to knee pain. The age ranged from 35 to 75 years with a mean $(\mathrm{SD})$ of $53.67 \pm 13.6$. Individual fitness levels and experience in trail walking varied from beginner to advanced. Of the 9 participants who completed the study, six were married, all had some or had completed post secondary education, five were working full-time and three were retired. Body mass index as assessed by self -reported height and weight categorized five participants in the normal weight category, three in the overweight category and one in the obesity class 2 category. Participants had a range of cancer types: breast cancer survivors $(n=4)$, thyroid cancer survivors $(n=2)$ and the remaining as cervical, brain colorectal and bladder cancer survivors $(n=4)$. The average participant was less than 3 years since cancer diagnosis $(n=5)$. At the time of diagnosis two participants were in stage 1, six participants with in stage 2 and one was unknown. The majority of participants had surgery $(n=8)$ and/or radiation $(n=7)$ to treat their cancer. At the time of the program all participants had been told but their treatments were complete with the majority reporting that their cancer was gone $(n=8)$.

\section{Quantitative findings}

Average attendance was $74 \%$ among the 9 participants who completed the program with a range from 7 to 15 out of 16 trail walks. The group average rate of perceived exertion was 12 over the course of the program. Participants were encouraged to complete one additional TW per week to make up for any missed group trail walks. Pre-post mean changes and results of the paired t-tests for primary and secondary outcomes over the 8-week program are depicted in Table 1. There was no significant reduction in the primary outcome of generalized anxiety $(p=$ .38), however a decline was seen over the 8-week program. There was a significant reduction in perceived stress $(p=$ $.03)$, and a significant reduction was seen when comparing the mean pre and post state anxiety scores of all 16 trail walks over the 8 -weeks $(p<0.001)$. None of the other secondary outcomes were statistically significant $(p>.05)$.

\section{Qualitative findings}

Four overarching themes, or benefits, emerged from qualitative data analysis: (a) benefits of program design, including accountability and safety, (b) physical benefits, including increased engagement of physical activity and self-efficacy, (c) psychological benefits, including anxiety alleviation and connection with nature, and (d) social benefits, including survivor camaraderie and perspective shifts towards cancer. These themes and corresponding subthemes are summarized in Table 2 .

Table 1 Pre-post changes in primary and secondary outcomes

\begin{tabular}{llll}
\hline Survey & $\begin{array}{l}\text { Pre-Score } \\
\text { mean } \pm \text { SD }\end{array}$ & $\begin{array}{l}\text { Post- Score } \\
\text { Mean } \pm \text { SD }\end{array}$ & P-value \\
\hline General Anxiety & $7.00 \pm 4.50$ & $5.22 \pm 4.30$ & .38 \\
State Anxiety & $35.32 \pm 1.23$ & $18.32 \pm 0.95$ & $<0.001$ \\
Health Related Quality of Life & $16.44 \pm 1.88$ & $16.44 \pm 1.42$ & 1.000 \\
Perceived Stress & $19.44 \pm 6.50$ & $14.62 \pm 6.42$ & .03 \\
Sleep Disturbances & $25.56 \pm 7.16$ & $23.00 \pm 7.53$ & .44 \\
Self-efficacy & $22.11 \pm 9.88$ & $22.89 \pm 8.37$ & .77 \\
Self-esteem & $21.33 \pm 4.53$ & $20.56 \pm 3.84$ & .52 \\
Psychological Well-being & $99.44 \pm 11.53$ & $101.00 \pm 9.70$ & .78 \\
Depression & $8.33 \pm 4.82$ & $5.89 \pm 4.29$ & .12 \\
\hline
\end{tabular}




\section{Benefits of program design}

Participants ability to successfully participate in the TW program were attributed to program accountability and safety. Participants expressed the challenges of making time for physical activity after cancer and acknowledged that commitment to the program assured accountability. For example, one participant stated that commitment contributed to schedule clarity:

I hadn't been making time for myself to have that kind of exercise...because my schedule's demanding, so when I told everybody I had taken on this commitment, these time blocks were now occupied. (Male, 66, Colon Cancer)

Similarly, a young working mother of two stated that her busy and demanding schedule prevented her from engaging in regular physical activity despite her enjoyment of it: "[The program] was a way for me to [be active] without relying on myself to organize it" (Female, 35, Thyroid Cancer).

In addition, participants expressed their challenges with continuing to be active, especially in the outdoors, once the program ended. Despite carrying shoes with her on the date of the interview, one participant (Female, 49, Breast Cancer) admitted the she has not walked since program completion due to the lack of ongoing commitment. The lack of accountability following program completion was further acknowledged as a barrier to ongoing TW adherence, despite the perceived benefits:

It was so refreshing to get outside and it was nice that I signed up, that it was to commit to do it, because if it was just me and myself I can easily discuss why I don't need to go today. (Female, 42, Brain Cancer)

Apart from accountability, a second benefit of program design was safety, which was especially identified by females who are active after cancer diagnosis. Some safety was experienced on account of capable program guides,

Table 2 Major themes and subthemes

\begin{tabular}{ll}
\hline Themes & Subthemes \\
\hline Program design benefits & Accountability \\
& Safety \\
Physical benefits & Physical activity engagement \\
& Physical activity self-efficacy \\
Psychological benefits & Anxiety alleviation \\
Social benefits & Connection with nature \\
& Survivor camaraderie \\
\hline
\end{tabular}

who provided hiking equipment and support as needed: "I didn't feel like I was tossed off into a big mountain and having to fend for myself, I felt very safe...you felt like wherever they were taking us it was going to be okay" (Female, 56, Breast Cancer). Safety was also experienced through the humour expressed by others in the group:

And then there are people there to watch you fail...[laughing]...totally exposed. But everyone was so supportive....in the first couple of hikes I didn't go as far as everyone and that was okay, someone stayed back with me and made me laugh about it, so that was really good. (Female, 43, Cervical Cancer)

\section{Physical benefits}

Participants reported that, while learning the importance of prioritizing physical activity in their life, improved competency in engaging in outdoor activity altered their thinking about how physical activity could be incorporated into daily living. One participant identified a shift in his prioritization of physical activity which has led to ongoing adherence:

I don't spend enough time in physical activity so that's where I think I partly connected to this. I know it's a need in my life but I don't make it a priority...[So] it's kept it on the front burner for me, like on Saturday we had a couple of hours so we said let's go for a hike. (Male, 68, Colon Cancer)

Similarly, hiking was discovered as an accessible physical activity: "I feel like hiking is easier to do on a whim" (Female, 35, Thyroid Cancer). Accessibility coupled with increased competency enabled participants to expand their understanding of available physical activities to participate in: "One of the tools in my toolbox is to go for a hike or even just go to a park and immerse myself in nature or find a quiet place" (Female, 43, Cervical Cancer).

Numerous participants identified increased exercise self-efficacy and physical fitness after completing the TW program. For example, one participant acknowledged that the program "increased my confidence" to believe that "I am active enough to take this on" (Female, 35, Thyroid Cancer). Several other participants noted that they "felt better each time" (Female 56, Breast Cancer) and noticed positive physical benefits regardless of relative difficulty of the hikes: "I mean physically I felt better, and I thought well that didn't take much to make a noticeable change" (Male, 66, Colon Cancer). The commitment to the program along with the social supports provided assisted in the improved fitness benefits and perceived ability to complete the hikes: 
I would be doing stuff around the house and then I would start to sweat profusely and get really, really tired and so I would stop pushing myself...but when you were with a group of people climbing a mountain you can't sit down and have a nap, you have to keep going and they taught me how to hike properly, how to keep a better pace and do all of that sort of thing so what I found then is that after only maybe two or three weeks I wasn't getting tired around the house. (Female, 43, Cervical Cancer)

Ultimately, noticeable changes in physical fitness and an appreciation for the growth achieved helped reinforce changes in exercise self-efficacy:

Overall, it's reminded me that I'm a strong person. I was always a healthy person before cancer and was always active and then during treatment I was very sedentary and it felt like I couldn't get back into it... I've learned...that I'm not a delicate flower that needs to be protected in bubble wrap...I fell a lot of times on the hike and I recovered and it reminded me that not everything is cancer related. (Female, 43, Cervical Cancer)

\section{Psychological benefits}

Participants identified positive impact from the program on their psychosocial states, specifically identifying the benefits derived from general program participation as well as immersion in nature. These benefits were experienced in response to the long-term health anxiety after cancer diagnosis due to fear of recurrence experienced by several participants: “You always hope that it doesn't come back. That is of course the big fear for most people" (Female, 43, Cervical cancer). That health anxiety often plagued individuals with questions of uncertainty and worry: "Any sort of physical ailment or little pain...automatically [has] your mind going, is this serious or not serious? What do I need to do? Do I need to talk to the doctor?" (Male, 66, Colon cancer).

Confronted with health anxiety, participants broadly felt that the TW program had a positive impact on their psychological state, specifically in anxiety alleviation. An increase in physical activity self-efficacy assisted one participant in reducing anxiety: "Part of my anxiety is thinking that I'm never going to be as strong, or as adventurous as I would have before so that's really shown me that I can keep going" (Female, 43 Cervical Cancer). For another individual, an increase in confidence and positive attitude was experienced well beyond the program itself:

What I noticed was after a few weeks of being a part of the program I felt I was handling things better.
Things were not getting me down as much and I was able to have a more calm and cheerful attitude towards it. (Female, 68, Breast Cancer)

The decrease in anxiety was especially highlighted when participants were still involved in post-cancer testing procedures, and utilized the program as means to curb their concerns:

Getting out twice a week with them, talking to people about it, getting out and exercising, really helped with my anxiety. It was the first time coming into my testing that I wasn't extremely anxious. I wasn't up worrying every single night. I took more the approach that it will be what it will be and I'll deal with it once I get to that. That was really what I took from everybody [in the group]: we can't change what's going to happen but we can change how we react to it. I was a lot more calm going into the testing. (Female, 50, Bladder Cancer)

For many of the participants, some of these reductions in anxiety were perceived to be due to being immersed in natural environments during trail walks. Connection to nature impacted one participant's attention to outside worries: "There were no distractions. I could stay in the moment, then I'm not worrying" (Female, 50, Bladder cancer). Further, time spent away from regular duties combined with immersion in the natural environment enabled a participant to reduce feelings of stress and worry:

I think if I go for a walk on urban streets, I feel it physically, but I know mentally I may not disconnect from responsibilities or other things the same as walking in the woods. There may be lots on my mind going in but I do find that the nature sort of calls after a while and you start to sort of notice other things: the moss on the trees and the sunlight coming through, and maybe after 10 or 15 minutes you start to realize that I stopped thinking about the stuff that I was worried about or stressed about. Maybe those are strong words, because maybe it wasn't, but sort of let go of stuff. (Male, 66, Colon cancer)

In addition to its direct link to a reduction in anxiety there were other perceived benefits of being immersed in nature on mental health. Primarily, participants appreciated the rich sensory engagement of the outdoors: "We were constantly chatting about the colors and the changing scenery and just appreciating the weather and so [the best part] probably was the forest. (Female, 76, Breast cancer). These sentiments were echoed by another participant who enjoyed the changing seasons: 
It's just so full of life, so even at this time of year it's just amazing part, most of the leaves were down so you are walking on the leaves so you are witnessing this sort of cycle of nature but at the same time there is life and birds and moths and...it's just...it's good. (Male, 66, Colon cancer)

For another, the gratitude of the outdoors and life in general contributed to a positive emotional response: "I am just so thankful. I do love trees. I feel like they are here to celebrate so I do touch them and hug them because I guess I'm just so thankful that I am still here" (Female, 42, Brain cancer).

For most participants, an escape from more urban settings and schedules contributed to increased positive benefits of the outdoors, such as: "Fresher air. Less noise and interruptions. No time frame to have to get back" (Female, 76 , Breast cancer). Though some participants regularly engaged in walks around their neighbourhoods, the benefits experienced in those residential areas were not valued as much as time spent outdoors: "I do think the nature piece was the most important for me. I think if it was just the same group going around town I don't know that I would have signed up for it" (Female, 35, Thyroid Cancer).

\section{Social benefits of the program}

Participants had varied experiences on the social benefits of being in a program with other cancer survivors. The majority of participants enjoyed engaging in physical activity in a group while a minority expressed that being in a group took away from the peace and quiet of being immersed in nature: "Everyone wants to chat and I sometimes think...let's just pause and look around...I guess I am more of an introvert" (Male, 66, Colon cancer). Additionally, some participants acknowledge feelings of anxiety and apprehension when initially beginning the program, but those feelings were alleviated on account of the group atmosphere:

It felt like everybody was really open and friendly and I mean, I was a little apprehensive because this whole idea of getting a bunch of cancer survivors together... is it going to be like a doomsday walk? [laughing]. But it was quite lighthearted and everyone was happy and upbeat (Female, 35, Thyroid cancer).

Despite those occasional feelings of introversion and apprehension, the group setting contributed to a sense of camaraderie within cancer survivors which assisted in anxiety alleviation for one participant: "I mean the hiking was great it really relieved the anxiety but it was more of a support group for me. For the first time I didn't feel alone" (Female, 50, Bladder cancer). When prompted as to whether the social support would have been experienced in the same manner if the group was not restricted to cancer survivors, there was a resounding sentiment that the shared cancer experiences were essential to positive camaraderie. For example, one participant expressed, "Wow, I fit in here, like, I'm not the odd man out...and just realizing that I am not alone" (Female, 50, Bladder cancer). For another participant, the group dynamics led to a mutual understanding of cancer experience:

Having gone through it themselves, and understanding what you went through and what it's like and sort of being able to talk to other people...I mean we wouldn't always talk about cancer and what's happening, but just knowing that they understand. (Female, 76, Breast cancer)

The general consensus however, was that while being with other cancer survivors was valuable, the majority of participants did not want to restrict discussions to cancer alone, and would sometimes realign themselves in the group walking formation to avoid the discussion on a particular day. One participant stated: "I didn't really want to talk about it. And I didn't particularly want to hear about it either." (Female, 68, Breast cancer). Similarly, another participant enjoyed the varied conversations and supports experienced through the program: "It was nice to be able to talk to people who were going through cancer about anything else but cancer" (Female, 43, Cervical cancer).

There were also many dimensions of perspective or paradigm shifts that occurred by engaging with other cancer survivors through this program. Participants expressed empowerment and a renewed desire to focus on their health. One participant stated: "I got a piece back of who I used to be. I made that connection from pre-cancer to post-cancer that I was still the same person" (Female, 43, Cervical cancer). Sharing experience with others reaffirmed for one participant that a cancer diagnosis does not necessitate a radically different lifestyle: "You can do more than you think...knowing that you can just keep going and...keep moving and keep physically active" (Female, 76, Breast Cancer). Finally, viewing other people struggle with cancer while maintaining an active life solidified for another participant the need to continue to prioritize physical activity into her life:

I saw another lady had just finished cancer like she had gone through the radiation or chemo, I'm not sure which one, but she was just free from treatment in a very short period of time. To see that she was actively out exercising and still able to live her life...If [my cancer] does reoccur, my ability to get through additional surgery or something is going to 
be much better if I am in physically better shape. So that's a positive influence and I guess it's just rearranging priority and translating that into a priority in my life. (Female, 50, Bladder cancer)

\section{Discussion}

An 8-week TW program in a diverse group of cancer survivors did not result in a reduction in generalized anxiety, psychological well-being, depression, sleep or exercise self-efficacy, but significantly reduced perceived stress and state anxiety. This study aimed to facilitate an understanding of the utility of a TW program for cancer survivors in increasing physical activity uptake and improving psychosocial health. To our knowledge this is one of the first studies that have combined physical activity and nature to improve psychosocial health in cancer survivors. It is apparent from participant experiences that there are many psychological benefits associated with being active in nature that are associated with a reduction in anxiety.

Living through a physical and psychological burden, such as cancer, is a form of chronic stress [32]. High levels of mental distress for sustained periods of time in cancer survivors can lead to anxiety [32]. Emerging evidence points to a synergistic relationship between the psychological benefits of physical activity and the restorative effects of exposure to nature, an association also acknowledged through the sense of escape and immersion in nature experienced by study participants [24]. Evidence supports that both physical activity and exposure to natural environments can greatly impact a person's psychological well-being by enhancing a person's mood, self-esteem, positive emotions, attentional and cognitive capacities, and reducing stress and anxiety [19, 22]. Negative mood symptoms such as stress and anxiety often co-occur [35]. Habitual rumination is associated with anxiety symptoms in cancer survivors and likely forms a negative feedback loop between ruminating on anxious thoughts/emotions, and anxiety symptoms [21]. Rumination patterns have been associated with the neural activity that takes place in the subgenual prefrontal cortex (sgPFC) of the brain [7]. Research has shown a 90-min walk in a park setting significantly decreased neural activity in the $\mathrm{sgPFC}$ and decreased self-reported rumination compared to a 90-min walk in an urban setting [7]. Similarly, studies show that green space has a positive effect on stress physiology and that a significant linear relationship exists between the degree of perceived greenness and the reduction in anxiety $[22,30]$. Often a person's favorite place offers emotional relief from any negative moods being experienced and gives the person an opportunity for emotional self-regulation, which includes stress relief [30]. The authors go on to suggest that natural places have restorative attributes that are inherently fascinating, allowing the person to experience "being away" from everyday stressors. While further research is needed to better understand the relationship between the exposure to nature and the impact it can have on an individual's psychological health $[7,13]$, finding that participants identified anxiety alleviation and positive emotions and attributed these changes to the sensory engagement provided by the natural environment provides support for a relationship. The psychological benefits of outdoor physical activity were further supported by the reductions perceived stress and trait anxiety after trail walks.

The American College of Sports Medicine (ACSM) supports physical activity as exercise prescription to help address the unique health challenges of cancer survivors [11]. There is "increasingly robust evidence" showing the positive effects of exercise for those living with and beyond cancer [11]. However, physical activity uptake among cancer survivors is low [15] and this may be due to low exercise self-efficacy post-cancer diagnosis [4]. A population of breast cancer survivors found that successful physical activity mastery experiences leads to an increase in exercise self-efficacy [4]. We also found that there were numerous descriptions of an increase in competency, empowerment, and physical fitness that resulted in an increased perspective of enhanced exercise self-efficacy. Exercise self-efficacy is also enhanced by social support in cancer survivors [6]. The majority of participants in our study found that engagement in the TW program with other cancer survivors was essential to their participation and this paralleled the literature [6]. Amongst individuals already exercising on a regular basis, research has shown that those who exercised outdoors, and whose activities were more nature related, showed lower levels of somatic anxiety compared to the those who exercised indoors [19]. In addition, larger reductions in state anxiety were observed in physical activities that took place in greener environments [22]. An outdoor environment may provide a good distraction during physical activity, as well as be a welcomed motivator through challenging exercise [30]. It is possible the actual enjoyment of the TW program led to greater adherence and motivation for participants to increase their physical activity level and this is further supported by the enhanced self efficacy denoted in participant qualitative interviews. To see a significant reduction in anxiety, the ACSM recommends 30-60 min of moderate to vigorous aerobic activity three times per week for 12 weeks. Response time was shortened to 6-12 weeks when aerobic and resistance training were combined twice a week. It is possible, that the present study's 8-week program may have been too short a timeframe to elicit a significant response in generalized anxiety. For instance, it is suggested that there is a dose-response relationship with aerobic exercise that leads to a greater depressive symptom reduction [11].

With the strong need for programming in cancer survivorship that improves cancer related side effects it is important to recognize some of the aspects of this trail 
walking program that participants deemed to be important for their success. The recurring sub-themes related to program design were accountability and safety. This suggests that effective program implementation would likely be a supervised program with instructors having the education to ensure participant safety. As well, the psycho-social benefits expressed by participants suggests values in prioritizing multi-participant programming. It is also likely that the TW program would need to be in lush green areas such as those chosen for this study in order to ensure that there was an overarching experience of natural exposure due to its reported psychological benefits in this population.

\section{Limitations}

Although the present study is amongst the first to look at how physical activity in a natural green environment affects anxiety in a cancer population, limitations need to be taken into consideration when interpreting results and considering future research.

A significant limitation of the current study is the small sample size, especially with respect to the quantitative analyses. The non-significant findings in the questionnaire-based outcomes may have been due to a lack of power. Only nine participants who completed the TW program completed exit interviews and therefore may have had more positive experiences with the program than the three participants who did not complete the program. In addition, there were varied participant experiences with TW that may have affected the impact of the program on their physical and psychological health. In order to ensure that the participants did not feel like they had to have a positive bias in their interview responses, a qualitative researcher who was independent of the program and had not previously met the participants conducted interviews. Another limitation stems from the baseline fitness of the participants. The study consisted of both active and sedentary participants which made it difficult to maintain a steady pace that would keep everyone at a moderate to vigorous intensity needed to reduce generalized anxiety. A future study could run separate cohorts grouping participants by fitness level, thus allowing better group pacing. Lastly, general anxiety was determined through pre-post surveys to see if there was a significant change. Biological markers such as cortisol would offer an alternative measure of generalized anxiety that is not based on self-report.

\section{Conclusions}

These findings help to further understanding of the utility of a TW program for cancer survivors in order to promote physical, psychological, and social health. Feasibility of a TW program would be contingent on access to natural areas for trail walking and an instructor led program with other cancer survivors. Further research with a larger sample size is required in order to fully assess the generalisability of this type of physical activity program for cancer survivors.

\section{Acknowledgements \\ The authors wish to acknowledge the contributions of the research assistants that were involved in the trail walking program as well as the cancer survivors that made this all possible. \\ Authors' contributions \\ IL was involved in study design, interview transcription, data analysis and manuscript writing. JP was involved in program design and implementation and manuscript writing. $C T$ was involved in program design, data analysis and manuscript writing. LB was involved in program design and manuscript writing. CN completed interviews, was involving in data analysis and manuscript writing. The authors read and approved the final manuscript.}

\section{Funding}

There was no funding associated with this research.

\section{Availability of data and materials}

The datasets generated and/or analysed during the current study are not publicly available due to the small sample size and the possibility of linking data, but are available from the corresponding author on reasonable request.

Ethics approval and consent to participate

Ethics approval was granted by the University of the Fraser Valley Human Ethics Board (1152-K19) and all participants provided written informed consent.

\section{Consent for publication}

Not applicable.

\section{Competing interests}

The authors have no competing interests.

\section{Author details}

${ }^{1}$ School of Kinesiology, University of the Fraser Valley, Chilliwack, BC, Canada. ${ }^{2}$ Hasakayne School of Business, University of Calgary, Calgary, AB, Canada.

${ }^{3}$ School of Health Studies, University of the Fraser Valley, Chilliwack, BC, Canada.

Received: 27 April 2020 Accepted: 13 October 2020

Published online: 19 October 2020

\section{References}

1. Abbott RA, Ploubidis GB, Huppert FA, Kuh D, Wadsworth ME, Croudace TJ. Psychometric evaluation and predictive validity of Ryff's psychological wellbeing items in a UK birth cohort sample of women. Health Qual Life Outcomes. 2006;4:76.

2. Abend R, Dan O, Maoz K, Raz S, Bar-Haim Y. Reliability, validity and sensitivity of a computerized visual analog scale measuring state anxiety. J Behav Ther Exp Psychiatry. 2014;45:447-53. https://doi.org/10.1016/j.jbtep. 2014.06.004

3. About Cancer Survivorship Research: Survivorship definitions. The National Cancer Institute; (Accessed 11 Oct 2012). Available at: http://dccps.cancer. gov/ocs/definitions.html.

4. Awick EA, Phillips SM, Lloyd GR, McAuley E. Physical activity, self-efficacy and self-esteem in breast cancer survivors: a panel model. Psychooncology. 2017;26(10):1625-31.

5. Bernd L, Decker O, Müller S, Brähler E, Schellberg D, Herzog W, et al. Validation and standardization of the generalized anxiety disorder screener (GAD-7) in the general population. Med Care. 2008;46(3):266.

6. Barber FD. Social support and physical activity engagement by cancer survivors. Clin J Oncol Nurs. 2012;16(3):84-98.

7. Bratman G, Hamilton J, Hahn K, Daily G, James J. Nature reduces rumination and sgPFC activation. Natl Acad Sci. 2015;112(28):8567-72. 
8. Blaschke S. The role of nature in cancer patients' lives: a systematic review and qualitative meta-synthesis. BMC Cancer. 2017;17(1):1-13. https://doi.org/ 10.1186/s12885-017-3366-6.

9. Burke S, Wurz A, Bradshaw A, Saunders S, West MA, Brunet J. Physical activity and quality of life in cancer survivors: a meta-synthesis of qualitative research. Cancers (Basel). 2017:9(5):53.

10. Canadian Cancer Statistics (2019) Canadian Cancer Society. Retrieved from: http://www.cancer.ca/ /media/cancer.ca/CW/publications/Canadian\%2 OCancer\%20Statistics/Canadian-Cancer-Statistics-2019-EN.pdf.

11. Campbell KL, Winters-Stone KM, Wiskemann J, May AM, Schwartz AL, Courneya KS, et al. Exercise guidelines for cancer survivors: consensus statement from international multidisciplinary roundtable. Med Sci Sports Exerc. 2019;11:2375.

12. CDC: Centers for Disease and Control. Anxiety and depression medicine use among cancer survivors; 2016. Retrieve from: https://www.cdc.gov/cancer/ dcpc/research/articles/anxiety_dep_med_survivors.htm.

13. Chang $C$, Chen $P$. Human response to window views and indoor plants in the workplaceHortScience: A Publication of the American Society for Horticultural Science; 2005. p. 5.

14. Demark-Wahnefried W, Morey MC, Clipp EC, Pieper CF, Snyder DC, Sloane R, et al. Leading the way in exercise and diet (project LEAD): intervening to improve function among older breast and prostate cancer survivors. Control Clin Trials. 2003;24(2):206-23.

15. Garcia DO, Thomson CA. Physical activity and cancer survivorship. Nutr Clin Pract. 2014:29(6):769.

16. Groen WG, Harten WH, Vallance JK. Systematic review and meta-analysis of distance-based physical activity interventions for cancer survivors (2013-2018): we still haven't found what we're looking for. Cancer Treat Rev. 2018;6:188-203.

17. Hann D, Winter K, Jacobsen P. Measurement of depressive symptoms in cancer patients: evaluation of the Centre for epidemiological studies depression (CES-D). J Psychosom Res. 1999;46(5):437-43.

18. Huang HY, Tsai WC, Chou WY, Hung YC, Liu LC, Huang KF, et al. Quality of life of breast and cervical cancer survivors. BMC Womens Health. 2017;17:30.

19. Lawton E, Brymer $E$, Clough $P$, Denovan A. The relationship between the physical activity environment, nature relatedness, anxiety and the psychological well-being benefits of regular exercisers. Front Psychol. 2017;8:1058.

20. Lee EH. Review of the psychometric evidence of the perceived stress scale. Asian Nurs Res. 2012;6(4):121-7 https://doi-org.proxy.ufv.ca:2443/10.1016/j. anr.2012.08.004

21. Liu J, Peh C-X, Simard S, Griva K, Mahendran R. Beyond the fear that lingers: the interaction between fear of cancer recurrence and rumination in relation to depression and anxiety symptoms. J Psychosom Res. 2018;111: 120-6. https://doi.org/10.1016/j.jpsychores.2018.06.004.

22. Mackay GJ, Neill JT. The effect of "green exercise" on state anxiety and the role of exercise duration, intensity, and greenness: a quasi-experimental study. Psychol Sport Exerc. 2010;11:238-45.

23. Martyn P, Brymer E. The relationship between nature relatedness and anxiety. J Health Psychol. 2016;21(7):1436-45.

24. Mitchell R. Is physical activity in natural environments better for mental health than physical activity in other environments? Soc Sci Med. 2013;91:130-4.

25. Neupert SD, Lachman ME, Whitbourne SB. Exercise self-efficacy and control beliefs: effects on exercise behavior after an exercise intervention for older adults. J Aging Phys Act. 2009;17:1-16.

26. Nguyen J, Brymer B. Nature-based guided imagery as an intervention for state anxiety. Front Psychol. 2018;9:1858

27. Plummer F, Manea L, Trepel D, McMillan D. Screening for anxiety disorders with the GAD-7 and GAD-2: a systematic review and diagnostic metaanalysis. Gen Hosp Psychiatry. 2016;39:24-31. https://doi.org/10.1016/j. genhosppsych.2015.11.005.

28. QSR International (2015) NVivo 11 [computer software]. Available from http://www.qsrinternational.com/.

29. Robins R, Hendin HM, Trzesniewski KH. Measuring global self- esteem: construct validation of single-item measure and the Rosenburg self-esteem scale. Personal Soc Psychol Bull. 2001;27:151.

30. Roe J, Aspinall P, Thompson CW. Coping with stress in deprived urban neighborhoods: what is the role of green space according to life stage? Front Psychol. 2017. https://doi.org/10.3389/fpsyg.2017.01760.

31. Rosenburg M. Society and the adolescent self-image. Princeton: Princeton University Press; 1965. p. p326.

32. Smith HR. Depression in cancer patients: pathogenesis, implications and treatment (review). Oncol Lett. 2015;9:1509-14. https://doi.org/10.3892/ol.2015.2944.
33. Viljayvergia D, Denlinger CS. Lifestyle factors in cancer survivorship: where we are and where we are headed. J Personalized Med. 2015;5(3):243-63.

34. White MP, Alcock I, Grellier J, Wheeler BW, Hartig T, Warber SL, et al. Spending at least 120 minutes a week in nature is associated with good health and wellbeing. Sci Rep. 2019;9:7730.

35. Yi JC, Syrjala KL. Anxiety and depression in cancer survivors. Med Clin North Am. 2017;101(6):1099-113.

36. Yu L, Buysse DJ, Germain A, Moul DE, Stover A, Dodds NE, et al. Development of short forms from the PROMIS ${ }^{\text {TM }}$ sleep disturbance and sleep-related impairment item banks. Behav Sleep Med. 2011;10(1):6-24. https://doi.org/10.1080/15402002.2012.636266.

\section{Publisher's Note}

Springer Nature remains neutral with regard to jurisdictional claims in published maps and institutional affiliations.
Ready to submit your research? Choose BMC and benefit from:

- fast, convenient online submission

- thorough peer review by experienced researchers in your field

- rapid publication on acceptance

- support for research data, including large and complex data types

- gold Open Access which fosters wider collaboration and increased citations

- maximum visibility for your research: over $100 \mathrm{M}$ website views per year

At $\mathrm{BMC}$, research is always in progress.

Learn more biomedcentral.com/submissions 